Área Abierta. Revista de comunicación

audiovisual y publicitaria

ISSN: 2530-7592 / ISSNe: 1578-8393

\title{
La conversión de Terrence Malick: una visión del mundo traducida al cine
}

\author{
Pablo Alzola Cerero ${ }^{1}$
}

Recibido: 28 de abril de 2020 / Aceptado: 9 de septiembre de 2020

Resumen. El hecho de que el cineasta estadounidense Terrence Malick se dedicara durante unos años a la filosofía académica y tradujera al inglés el opúsculo De la esencia del fundamento de Martin Heidegger es tomado por algunos autores como clave interpretativa de su cine. Este artículo parte del concepto de mundo del filósofo alemán, tema central del citado opúsculo, y sus presuntas influencias en la filmografía del director con el objetivo de poner en duda esta afinidad y sugerir, en cambio, la hipótesis de que las películas de Malick están alentadas por una visión del mundo de raíces cristianas. La probabilidad de esta hipótesis será mostrada por una vía negativa, detectando algunas carencias de los estudios que vinculan a Heidegger con Malick, y por una positiva, analizando el significado de sus filmes desde la experiencia de conversión religiosa que estos parecen suscitar en los espectadores.

Palabras clave: Terrence Malick; Martin Heidegger; Cristianismo; Mundo; Espectador; Conversión

\section{[en] The Conversion of Terrence Malick: A Worldview Translated into the Film Medium}

\begin{abstract}
The fact that American filmmaker Terrence Malick devoted some years of his life to academic philosophy and translated into English Martin Heiddegger's The Essence of Reasons is understood by some authors as an interpretive key to his body of work. This article draws upon the German philosopher's concept of world, which lies at the core of the aforesaid text, and its presumed influences in the director's filmography with the objective of questioning this connection and suggesting, in turn, the hypothesis that Malick's films are nurtured by a worldview of Christian roots. The feasibility of this hypothesis will be supported in a negative way, by identifying some deficiencies in the studies that connect Heidegger with Malick, and in a subsequent positive way, by analysing the meaning of his films from the experience of religious conversion that they seem to elicit in their viewers.
\end{abstract}

Key words: Terrence Malick; Martin Heidegger; Christianity; World; Spectatorship; Conversion

Sumario. 1. Introducción. 2. Heidegger en la gran pantalla. 3. La legitimidad de un "cine heideggeriano". 4. Una conversión a través del cine. 5. La transformación de la mirada. 6. Conclusiones 7. Financiación. 8. Bibliografía.

Cómo citar. Alzola Cerero, Pablo (2020). La conversión de Terrence Malick: una visión del mundo traducida al cine. Área Abierta. Revista de comunicación audiovisual y publicitaria 20 (3), 353-369, http://dx.doi.org/10.5209/arab.69075

\footnotetext{
Universidad Rey Juan Carlos (España)

E-mail: pablo.alzola@urjc.es

ORCID: https://orcid.org/0000-0002-3397-9505
} 


\section{Introducción}

En otoño de 1969, el futuro cineasta Terrence Malick entró a formar parte de la primera promoción del American Film Institute Conservatory. Aquel año había sido publicada la traducción al inglés que él mismo hizo del opúsculo de Martin Heidegger Vom Wesen des Grundes - 1929; The Essence of Reasons, en inglés-. En cuestión de meses, la trayectoria de aquel joven de veintiséis años había dado un brusco viraje: de profesor sustituto de filosofía a director de cine en ciernes. Aunque es posible que aquel viraje no fuese tal: con el paso del tiempo, los largometrajes dirigidos por el cineasta texano han sido vistos por algunos autores como la traducción al lenguaje cinematográfico de las preocupaciones que ya había abordado en el terreno de la filosofía académica durante su major de Filosofía en la Universidad de Harvard, su inacabada tesis doctoral en el Magdalen College de Oxford y su breve estancia como profesor sustituto en el MIT. Algunos sugieren, tal y como apunta Sinnerbrink, que su trasfondo filosófico "configuró la subsiguiente carrera de Malick como cineasta, de tal modo que sus películas se entienden mejor como intentos de proyectar aspectos de lo que Heidegger pudo haber pensado filosóficamente" (2019: 3).

La introducción a la traducción inglesa del citado texto de Heidegger, escrita por Malick, bien podría ser tomada con una bisagra que conectase los intereses filosóficos del futuro director con su posterior obra cinematográfica. En dicha introducción, Terrence Malick afirma que el tema en torno al cual gira De la esencia del fundamento (Vom Wesen des Grundes, 1929) es el concepto de "mundo" (Welt), y explica cómo este concepto no trata, según Heidegger, de la totalidad de las cosas, sino de "aquello en cuyos términos las entendemos, aquello que les da medida y finalidad y validez en nuestros esquemas" (Malick, 2016 [1969]: 252). El empeño del filósofo alemán por definir qué es el mundo responde — prosigue Malick—a la importancia de "explicar por qué debemos, y no menos cómo podemos, compartir ciertas nociones sobre la medida y la finalidad y la validez de las cosas" (2016: 252). A menudo se ha tratado de entender el concepto de mundo como un punto de vista o una interpretación particular de las cosas cuando en realidad lo que quiere decir Heidegger con este concepto es "que ningún otro es posible" (Malick, 2016: 253). De haber un mundo, este ha de ser único. "No hay otro mundo, sino este" — there ain't no world, but this one-, son las palabras del sargento Welsh al soldado Witt al comienzo de La delgada línea roja (The Thin Red Line, 1998), posiblemente el filme de Malick sobre el que más se ha escrito en conexión con Heidegger.

La dificultad que se suele achacar al filósofo alemán está —afirma el futuro cineasta - en que "ninguno de sus conceptos, incluido el concepto de mundo, pueden ser entendidos hasta que uno no sabe cómo sacarles provecho" (Malick, 2016: 253). En este sentido, detrás de la tarea de traducir a Heidegger podría haber un intento de Malick por sacar provecho al concepto de mundo, por conocer su alcance y sus posibilidades, y así lograr entenderlo. No obstante, su repentino abandono de la carrera académica se nos presenta, a primera vista, como un fracaso en dicho intento. Heidegger desiste de su uso del alemán común y crea su peculiar lenguaje, porque el

La traducción de las voces en off y diálogos de la versión original en inglés sigue casi siempre la de los subtítulos en castellano disponibles en la edición española en DVD, aunque con pequeñas modificaciones allí donde esta traducción no se ha considerado ajustada. Cfr. La delgada línea roja [DVD distribuido en España por 20th Century Fox Home Entertainment España, Dep. Legal B-46.331-2002]. 
primero "no satisface sus propósitos; y no los satisface - escribe Malick — porque él tiene propósitos nuevos y diferentes" (2016: 254). Del mismo modo, podría decirse que Malick no fracasó ni tampoco abandonó la filosofía; más bien, dejó de lado su versión académica porque no satisfacía sus propósitos. La pregunta sobre cuáles son estos propósitos - y sobre si sobrepasan el lenguaje conceptual y, tal vez, al mismo Heidegger - no puede ser respondida desde el terreno de la filosofía académica, sino desde el lenguaje cinematográfico que Malick ha ido creando desde su primer largometraje, Malas tierras (Badlands, 1973), hasta su última película estrenada, Vida oculta (A Hidden Life, 2019). Es posible que Terrence Malick nunca haya dejado de ser un traductor, uno cuyas preocupaciones le han ido empujando a dar con un nuevo lenguaje al que poder traducirlas.

El presente artículo busca estudiar la noción de mundo en la filmografía de Terrence Malick con el objetivo de discernir, a grandes rasgos, hasta qué punto es legítimo hablar de un influjo de la filosofía de Heidegger en su cine o, por el contrario, en él sobresalen otras influencias. En las últimas dos décadas han proliferado los textos académicos — procedentes del área de los estudios de cine o film studies y, concretamente, de la rama conocida como film-philosophy - que tratan de explicar los filmes de Malick a la luz del pensamiento heideggeriano. Entre ellos destacan los estudios de Furstenau y MacAvoy (2007 [2003]), Clewis (2003), Sinnerbrink (2006), Silverman (2009), Dreyfus y Prince (2009), Woessner (2011), Rybin (2011) y Tucker (2011). En general, estos textos no pretenden entender los filmes del cineasta texano como meras ilustraciones de conceptos heideggerianos; al contrario, procuran "usar los conceptos para definir cómo podemos entender el cine de Malick” (Rybin, 2011: 14). Aunque, lo que casi todos ellos presuponen es que dicho cine guarda, de un modo u otro, una afinidad con la filosofía de Heidegger. Las páginas siguientes tratarán de poner en duda dicha afinidad, y plantearán la hipótesis de que este cine, y la noción de mundo que presenta, se comprende mejor - como sugiere Barnett (2013: 23) - "dentro de la tradición [...] cristiana, y no tanto como un punto de intersección entre los intereses espirituales y heideggerianos de Malick".

El objetivo que guía este estudio ha determinado su metodología. En primer lugar, se ha esbozado el concepto de mundo, tal y como lo sostiene Heidegger, tomando como apoyo tanto algunos textos del filósofo alemán —Ser y tiempo (2012 [Sein und Zeit, 1927]) y De la esencia del fundamento (2001 [Vom Wesen des Grundes, 1929]) - como las interpretaciones de Heidegger hechas por los analistas de Malick citados más arriba. En segundo lugar, se han señalado las principales carencias que — según autores como Harrison (2020) y Fijo (2019), entre otros- conlleva la aplicación de dichas interpretaciones al cine de Malick. Seguidamente, se han analizado algunos elementos narrativos y estéticos de las películas de Malick con el fin de proponer cómo en ellas — volviendo a las palabras del cineasta_ " "aquello en cuyos términos entendemos las cosas, aquello que les da medida y finalidad y validez" no responde al concepto de mundo heideggeriano, sino a una visión del mundo de raíces cristianas.

Debido a las limitaciones de este artículo, se ha optado por analizar una selección de fragmentos donde la convergencia de la voz en off y la mirada de la cámara sugiere un modo particular de dotar de sentido a las cosas; ya que muchos de los textos que conectan a Malick con Heidegger, con los que este artículo dialoga, presentan este mismo enfoque. Estos fragmentos proceden de todos los largometrajes de ficción dirigidos por el cineasta y estrenados hasta la fecha: Malas tierras (Badlands, 
1973), Días del cielo (Days of Heaven, 1978), La delgada linea roja (The Thin Red Line, 1998), El nuevo mundo (The New World, 2005), El árbol de la vida (The Tree of Life, 2011), To the Wonder (2012), Knight of Cups (2015), Song to Song (2017) y Vida oculta (A Hidden Life, 2019) ${ }^{3}$.

\section{Heidegger en la gran pantalla}

Es habitual encontrar en el cine de Malick personajes que parecen expresar con sus voces en off las mismas preocupaciones evocadas por la mirada silenciosa de la cámara. Aludiendo a la noción de mundo, en Malas tierras el personaje de Holly dice - después de haberse fugado de casa con su amante Kit - que "el mundo era como un planeta lejano al que ya no podía regresar. Pensé en qué lugar tan hermoso era, lleno de cosas que la gente podía mirar y disfrutar" " the world was like a faraway planet, to which I could never return. I thought what a fine place it was, full of things that people can look into and enjoy]. En To the Wonder, el personaje de Marina expresa su vacío interior con una voz en off semejante a la de la adolescente interpretada por Sissy Spacek: "El mundo, tan lejos. Un fantasma. Cenizas"5 [The world so far away. A ghost. Ashes]. Aunque posiblemente las palabras más destacadas en torno a dicha noción son las del diálogo, antes citado, que mantienen Welsh y Witt en La delgada línea roja, a bordo del barco que les lleva al frente de batalla. "En este mundo, un hombre por sí solo no es nada. Y no hay más mundo que este" [In this world, a man himself is nothing. And there ain't no world, but this one], sostiene Welsh. "Ahí te equivocas, Top — le rebate Witt—. Yo he visto otro mundo. A veces pienso que solo fue mi imaginación" [You're wrong, there, Top. I've seen another world. Sometimes I think it was just my imagination].

En su estudio sobre esta última película, Chion señala cómo un rasgo común a las voces en off, y a algunos diálogos, del cine de Malick es que transmiten "un comentario libre, a menudo atemporal" (2004: 56), sobre cuestiones de hondo calado teórico. Esta cualidad atemporal de su cine, tan clara en el uso que hace de la palabra, ha llevado a algunos autores a concluir que, "dado que fue la investigación del concepto de mundo la que atrajo gran parte de la atención de Malick como incipiente filósofo", tal vez "vio en el cine una oportunidad de abordar este tema de un modo más productivo, o al menos más significativo" (Woessner, 2011: 141). La afinidad entre el cine de Terrence Malick y la filosofía de Martin Heidegger es una suposición de la que dichos autores parten al desarrollar un análisis de este cine desde conceptos heideggerianos. Parece necesario, por tanto, comenzar con un breve esbozo de cómo el filósofo alemán entiende el concepto de mundo, en el que se centra este artículo, para más tarde examinar las posibilidades que tiene este concepto de ser trasladado a la obra de Malick.

Quedan excluidos el cortometraje Lanton Mills (1969), realizado por el cineasta como proyecto final de sus estudios en el American Film Institute, y el largometraje documental titulado Voyage of Time (2016).

4 De nuevo, la traducción de las voces en off y diálogos de la versión original en inglés sigue casi siempre la de los subtítulos en castellano disponibles en la edición española en DVD, aunque hay pequeñas modificaciones allí donde la traducción no se ha considerado ajustada. Cfr. Malas tierras [DVD distribuido en España por Memory Screen, Dep. Legal B-25.174-2012].

5 La traducción de las voces en off y diálogos de la versión original es del autor, a partir de la edición inglesa en DVD. Cfr. To the Wonder [DVD distribuido en el Reino Unido por Studiocanal Limited]. 
Para Heidegger, el mundo no es un concepto espacial; tampoco es una entidad, formada por un conjunto de cosas, con la que el ser humano pueda relacionarse de acuerdo con un esquema sujeto-objeto. Es, más bien, el horizonte de nuestra existencia cotidiana; un horizonte que abarca las relaciones y significados que constituyen nuestra vida. En nuestro trato cotidiano con las cosas - explica el filósofo en el capítulo tercero de Ser y tiempo (2012 [Sein und Zeit, 1927]) - estas se nos descubren como útiles de los que podemos disponer; asimismo, los útiles están relacionados con otros útiles, y estos a su vez con una tarea orientada a un propósito que, siguiendo la cadena, nos remite a otros propósitos los cuales, finalmente, tienen como referencia última nuestra propia existencia. "Esta totalidad de relaciones ensambladas, intrínsecamente referidas al $\operatorname{Dasein}^{6}$ y a las que este permanentemente se refiere es el fenómeno del mundo" (2006: 89), apunta Rodríguez. Al mismo tiempo, este entramado de relaciones ha de ser previo a nuestra experiencia o a nuestro conocimiento de él, pues es la condición de posibilidad de toda experiencia y de todo conocimiento. Antes de que lo captemos, ya nos encontramos inmersos en él. "El mundo - sostiene Heidegger - es [...] algo 'en lo que' el Dasein en cuanto ente ya siempre ha estado" (La cursiva es del original. 2012: 76).

Este concepto de mundo es uno de los ejes que vertebran el opúsculo que traduciría Terrence Malick, De la esencia del fundamento (2001 [Vom Wesen des Grundes, 1929]). En este texto, dicho concepto va unido a otro que, como el propio Heidegger reconoce, hunde sus raíces en el cristianismo: el concepto de trascendencia ${ }^{7}$. "Trascendencia significa traspasamiento. Trascendente - que trasciende- es lo que lleva a cabo ese pasar más allá y se mantiene en él" (2001: 137), apunta Heidegger. La trascendencia consiste en ir más allá de todo ente para dirigirse hacia el mundo; así, es el mundo - y no Dios, como en el caso del cristianismo - el hacia dónde del movimiento de la trascendencia: "A eso a lo cual el Dasein, como tal, trasciende lo llamamos el mundo" (La cursiva es del original. Heidegger, 2001: 139). De nuevo, el mundo es presentado aquí como ese amplio horizonte desde el cual el ser humano se entiende a sí mismo; como un entramado de relaciones que tienen en el hombre su centro de gravedad, su razón de ser. Por otro lado, las distancias entre la filosofía de Heidegger y el cristianismo serán de gran interés para la interpretación de la filmografía de Malick que propone este estudio ${ }^{8}$.

Algunos autores han tomado el concepto heideggeriano de mundo como una ventana desde la que asomarse al cine de Malick, dado que - tal y como se ha indicado más arriba - fue el propio cineasta quien tradujo al inglés un texto de Heidegger

\footnotetext{
"A este ente que somos en cada caso nosotros mismos, y que, entre otras cosas, tiene esa posibilidad de ser que es el preguntar, lo designamos con el término Dasein", escribe Heidegger en Ser y tiempo (La cursiva es del original. 2012 [1927]: 7). Dentro del pensamiento heideggeriano, el hombre desempeña un papel de primer orden. Tanto es así que Heidegger se refiere a él como el "ente ejemplar", pues "se destaca frente a los demás entes" (2012: 11) en la medida en que es capaz de hacerse preguntas y, sobre todas, la más fundamental: la pregunta por el ser. Los números de página de las obras de Heidegger citadas siguen la edición original en alemán.

"La idea de 'trascendencia', que el hombre sea algo que tiende más allá de sí mismo, tiene sus raíces en la dogmática cristiana" (Heidegger, 2012: 49), escribe en Ser y tiempo.

8 También en De la esencia del fundamento (2001: 143-145) encontramos un interesante excurso sobre el cristianismo, donde Heidegger explica cómo el concepto de mundo (kósmos) tiene — según el Evangelio de Juan y algunas Epístolas de San Pablo - un doble significado: el conjunto de la creación, por un lado, y la posición del hombre alejado de Dios y volcado hacia los bienes temporales, por otro. El concepto heideggeriano está relacionado con el segundo significado, de tipo antropológico.
} 
centrado en dicho concepto. Stanley Cavell, supervisor de su tesis de fin de carrera en Harvard, titulada The Concept of Horizon in Husserl and Heidegger (1966), fue el primero que habló de un filme de Malick en estos términos. "Creo que la película - escribe Cavell aludiendo a Días del cielo al comienzo de la edición ampliada de El mundo visto - contiene de hecho una visión metafísica del mundo, aunque creo que sentimos que no hemos visto nunca de manera suficiente la escena de la existencia humana [...] completamente realizada así antes en el cine" (2017 [1979]: 18). Poco después, el filósofo de Harvard subraya "el conocimiento de que Malick tradujo hace años De la esencia del fundamento de Heidegger" (Cavell, 2017: 19) y explica cómo, a su juicio, el cineasta ha logrado proyectar un mundo de gran belleza, tejido por objetos presentes en la pantalla y a la vez ausentes, a través de su película. Estas intuiciones de Cavell, apenas desarrolladas, harían correr ríos de tinta con el paso del tiempo.

Tomando las ideas de Cavell como punto de partida, Furstenau y MacAvoy afirman que La delgada línea roja también contiene una singular visión del mundo, donde la pertenencia originaria del hombre a ese entramado de relaciones ha sido sustituida por "una racionalidad tecnológica, según la cual las cosas en el mundo las personas incluidas - son vistas de modo puramente instrumental" (2007 [2003]: 184). En esta época de relaciones de dominio — simbolizada en el filme mediante el conflicto bélico - estos autores dicen que Malick ha asumido el papel "del poeta durante lo que Heidegger llamó 'tiempos de penuria', en los que el mundo ha sido vaciado de misterio y profundidad" (Furstenau \& MacAvoy, 2007: 182). De forma similar, el análisis de Clewis sobre esta película señala cómo algunos de sus protagonistas — Witt, y más tarde Welsh — despiertan a una actitud de asombro frente al mundo netamente heideggeriana: "Desde el punto de vista de Heidegger - $-\mathrm{y}$, afirmo, también desde el de Malick_- este estado de ánimo abre el mundo en su verdad y lo revela como 'realmente' es" (2003: 23). El estudio de Sinnerbrink, en sintonía con los dos anteriores, afirma que las películas de Malick potencian "la capacidad del cine para despertar distintos tipos de sintonía o estados de ánimo mediante el sonido y la imagen, revelando aspectos, de otro modo ocultos - visuales, sonoros, afectivos y temporales - , de nuestro finito estar-en-el-mundo" (2006: 36). Tanto Furstenau y MacAvoy como Clewis y Sinnerbrink hablan, en definitiva, de cómo este cine ha conseguido rescatar el concepto de mundo a través de un singular lenguaje visual y sonoro que va orientado a crear una experiencia afectiva en el espectador.

En relación a esto último, algunos autores sostienen que los filmes de Malick buscan que el espectador experimente la finitud, los límites, de su propio mundo. Esta es la tesis de Silverman en su análisis de La delgada línea roja, donde dice que los personajes y los espectadores somos invitados a morar en un "mundo finito" (2009: 132), más allá del cual no hay nada. "Si no he sido capaz de describir la experiencia de ver La delgada línea roja sin acudir a metáforas heideggerianas, esto es porque Malick está más interesado en el Ser que en los personajes o en el relato, y porque para él [...] no hay mundo más allá del nuestro; no hay un más allá al que podamos escapar" (2009: 110-111), escribe Silverman. En esta línea, Dreyfus y Prince (2009) y Woessner (2011) destacan cómo muchos filmes de Malick retratan el colapso de un mundo, en especial La delgada línea roja y El nuevo mundo; la guerra y el dominio colonial, respectivamente, sumergen a los protagonistas de estas últimas en un estado de angustia por el cual su mundo comienza a tambalearse. "La noción de angustia de Heidegger es lo que conduce al preguntar filosófico. Solo cuando estamos angus- 
tiados - apunta Woessner - indagamos la estructura y el significado del mundo" (2011: 144). La finitud es abordada por Rybin (2011) y Tucker (2011) desde la idea del combate entre mundo y tierra en que, según Heidegger, consiste toda obra de arte; una lucha entre el obrar humano abierto y la materia impenetrable ${ }^{9}$. De acuerdo con estos autores, el combate de la obra de arte sería evocado por el cineasta texano mediante una "asimetría entre la percepción humana - ya sea la del espectador o la de los personajes - y la percepción de la cámara cinematográfica" (Rybin, 2011: 18). Ciertamente, la cámara de Malick queda muchas veces alejada de ese mundo finito, articulado tanto por los personajes como por los espectadores, mostrándonos imágenes de una naturaleza que permanece indescifrable frente a estos.

\section{La legitimidad de un "cine heideggeriano"}

Después de exponer brevemente el significado del concepto de mundo de Heidegger, y de revisar algunas interpretaciones del cine de Terrence Malick desde este concepto, surge la pregunta por la legitimidad de tales interpretaciones. En última instancia, esta pregunta se desdobla en dos: si acaso la filosofía puede ser traducida al cine, por un lado, y si las películas de Malick son un caso de "cine heideggeriano" (Woessner, 2011), por otro. La bibliografía sobre la primera cuestión es amplia ${ }^{10} \mathrm{y}$, por ello, tratar de responderla desbordaría el objeto del presente estudio. En Hitchcock filósofo Pippin logra resumir el fondo de este problema con otra pregunta: "¿Cómo puede esa narrativa visual ficticia, que concierne a esas personas ficticias en particular y a acontecimientos ficticios particulares [...] ser portadora de una significación general?" (La cursiva es del original. 2017: 22). En efecto, el alcance universal de los conceptos filosóficos parece contrario a las narraciones concretas del cine.

No obstante, tal vez la filosofía de Heidegger sea una de las excepciones a lo dicho, ya que su centro de atención es siempre el hombre en su particularidad. Su recurrente expresión "en cada caso", referida a la existencia humana, es prueba de ello: "la existencia es decidida en cada caso tan solo por el Dasein mismo, sea tomándola entre manos, sea dejándola perderse" (Heidegger, 2012: 12), escribe en Ser y tiempo. Así, el filósofo alemán "quiere dar a entender que el hombre es lo que él en cada caso decide ser, que es proyecto de sí mismo, tarea de su propia realización" (Colomer, 2002: 471). Este énfasis de Heidegger en la existencia práctica e histórica del ser humano ha llevado a algunos a señalar las afinidades entre su filosofía y el medio cinematográfico. "¿No será que mucho de lo que Heidegger, [...] intenta decir, casi infructuosamente, forzando a la lengua alemana, obligándola a generar frases difícilmente inteligibles [...], sería mucho mejor expuesto a

Véase su conferencia El origen de la obra de arte (Heidegger, 2010 [Der Ursprung des Kunstwerkes, 1935/36]). Por ejemplo: "El ser-obra de la obra consiste en la disputa del combate entre el mundo y la tierra" (2010: 38). Este combate, explica Leyte, es "un acontecer constituido dualmente como abrirse y cerrarse: en el ponerse en pie y abrirse un mundo, algo se cierra, y en el producirse y abrirse la tierra se manifiesta su propio cerrarse" (2016: 40).

10 Veánse, por ejemplo, Filosofia y cine (2020), coordinado por Horacio Muñoz Fernández; Hitchcock filósofo de Pippin (2017); The Routledge Companion to Philosophy and Film, editado por Livingstone y Plantinga (2009); Thinking on Screen de Wartenberg (2007); Film as Philosophy, editado por Read y Goodenough (2005); On Film de Mulhall (2016 [2001]); Cine: 100 años de filosofía de Cabrera (2015 [1999]) o El mundo visto de Cavell (2017 [1979]), entre otros. 
través de imágenes surgidas a través del desplazamiento calmo y atento de una cámara de cine?" (2015 [1999]: 19), plantea Cabrera en su libro de cine y filosofía. Suponiendo esta afinidad entre Heidegger y el séptimo arte, es pertinente contestar ahora a la segunda pregunta, sobre si las películas de Malick son un caso de "cine heideggeriano".

Frente a los autores citados más arriba, favorables a una lectura del cine de Malick desde el pensamiento de Heidegger, hay otros que ponen en duda la legitimidad de estas interpretaciones. A este respecto, es relevante el estudio de Harrison (2020), pues presenta una síntesis de esta última postura. Según la autora, un acercamiento a la obra de Malick desde la filosofía de Heidegger presupone la existencia de una especie de subtexto filosófico oculto, que solo podría ser desenterrado con la ayuda de conceptos heideggerianos. Harrison ensaya hábilmente estas presuposiciones, para más tarde rebatirlas, tomando la película El nuevo mundo e interpretando algunas de sus escenas — como las de los indios Powhatan viviendo en comunión con la naturaleza, al comienzo; o la de Pocahontas, Rolfe y el hijo de ambos jugando a derramar el agua de una jarra, hacia el final - desde conceptos heideggerianos como "habitar" (Wohnen), "cosa" (Ding) o "cuaternidad" (Geviert) ${ }^{11}$. Articular un análisis desde estos conceptos implicaría tomar este filme como una especie de prueba empírica “capaz de corroborar el edificio metafísico de Heidegger", apunta Harrison (2020: 209). Esto conllevaría afirmar, de modo más general, que el significado del filme está sujeto a una "teoría extra-cinematográfica" (2020: 210), algo que la autora niega. Por otra parte, Harrison añade que un cine tan poético como el de Malick es, en muchas ocasiones, lo suficientemente ambiguo como para ser reelaborado al servicio de puntos de vista filosóficos diferentes a los de Heidegger.

De modo similar, Fijo advierte — basándose en el estudio de Critchley (2002) sobre La delgada línea roja - contra el peligro de reducir el "estudio del cine de Malick a un subtexto filosófico que sería la llave para entender su significado" (2019: 125). Al mismo tiempo, este autor plantea una aproximación a los filmes de Malick desde ideas cristianas como son las de "creación", "gracia", "comunión" o "providencia"; así, estos filmes presentarían "un sentido que el pensador alemán [Heidegger] no asume: para Malick todo en la naturaleza humana y en el cosmos lleva a un Creador providente" (Fijo, 2017: 170). La dimensión religiosa de su cine "es tan intensa, en fondo y forma, que pretender abordarla con categorías meramente filosóficas conduce a estudios incompletos" (2019: 103), sostiene Fijo a propósito de El árbol de la vida; $\mathrm{y}$, más adelante, reitera que "la filosofía no basta para acercarse a la obra de Malick [...] se hace imprescindible el manejo de una estética, de una poética permeada por las categorías de la fe católica" (2019: 230).

En resumen, las tesis de Harrison y Fijo, representativas de otros enfoques similares, se oponen a la interpretación de Malick desde Heidegger por dos motivos: en primer lugar, porque la existencia de un subtexto filosófico oculto presupondría que el lenguaje del cine está incompleto sin la intervención de un espectador privilegiado - conocedor del pensamiento de Heidegger —; en segundo lugar, porque — como afirma Fijo - la lectura filosófica de este cine es parcial: es preciso acudir a categorías procedentes de la fe cristiana. Tal y como se intentará mostrar en lo que sigue, estos dos motivos son ciertos e invalidan, en gran medida, una interpretación del cine

Véase el segundo epígrafe del artículo de Harrison, titulado "Being-in-the-(new)-world", en "The New World: Heideggerian or Humanist Cinema?" (2020: 203-209). 
de Malick que se ajuste estrictamente a conceptos heideggerianos, como el concepto de mundo aquí tratado ${ }^{12}$.

En alusión al primer motivo, es verdad que el cine de Malick transmite el sentido de una búsqueda filosófica, tanto a través de sus personajes - su uso introspectivo de la voz en off, sobre todo- como mediante el uso del lenguaje cinematográfico; pero decir que esta búsqueda ha de seguir las pautas de una filosofía concreta parece excesivo. Pippin escribe que "de algunas películas puede decirse que tratan de iluminar algo sobre la conducta humana que de otro modo apenas entenderíamos" (2017: 20). Esto es lo que hacen las películas de Malick y, en esta medida, es posible calificarlas de "filosóficas". Se trata, en cualquier caso, de una filosofía alejada de su profesionalización académica, y más próxima a la originaria vocación moral de la filosofía, es decir, a su capacidad de acompañar y examinar las vidas ordinarias de los seres humanos (Cavell, 2007 [2004]: 27). Es legítimo decir, por consiguiente, que el cine de Malick está atravesado por una búsqueda de sentido ${ }^{13}$. Volviendo al segundo motivo, defendido por Fijo, queda por dilucidar si este es un sentido religioso y, más concretamente, cristiano.

\section{Una conversión a través del cine}

Es curioso observar cómo, en su introducción a la traducción inglesa del opúsculo De la esencia del fundamento, Malick se refiere a la tarea de interpretar un texto religioso y menciona las peculiaridades que conlleva dicha tarea:

Cuando se trata de adivinar los propósitos de Heidegger, sus argumentos y descripciones no serán de mucha ayuda, o solamente ayudarán o dejarán de ayudar al modo de, por ejemplo, la exégesis de un texto religioso. Uno sospecha que no son estrictamente argumentos o descripciones, sino que están pensados para hacer que estos procedimientos, y la correcta aplicación de ellos, sean posibles. Asumen que ya sabemos dónde buscar sus claves [...] y que, en la medida en que ya lo sabemos, compartimos necesariamente sus propósitos y no necesitamos depender de sus argumentos (La cursiva es del original. Malick, 2016: 254).

De sus palabras se infiere que esta tarea es difícil, comparable a la lectura del filósofo alemán, y también que el sentido de un texto religioso no ha de ser alcanzado por medio de la demostración - "sus argumentos y descripciones"- sino más bien por otra vía, más cercana a la aceptación, a leer el texto desde un significado que ha sido recibido. Esta breve alusión a la escritura religiosa bien podría ser vista como un anticipo del que más tarde sería el verdadero propósito del cine de Malick: un propósito no tanto filosófico sino religioso. De ser así, Malick seguiría siendo un traductor, pero de otro tipo: un traductor de la Biblia, el texto religioso

12 A este respecto, el presente artículo busca revisar las ideas propuestas por el estudio: “Al encuentro de la muerte: una lectura del primer cine de Terrence Malick desde la filosofía de Martin Heidegger” (Alzola, 2016).

13 En lo relativo a sus personajes: "Los protagonistas centrales en los filmes de Terrence Malick están atrapados en, o conducidos por, una búsqueda: hacia un tipo de vida diferente, un sentido del yo, una razón de ser, o una presencia espiritual en el mundo" (Patterson, 2007 [2003]: 1). O también: los personajes de Malick son "seres humanos insatisfechos, que quieren saber lo que son, dominados por una nostalgia de infinito" (Fijo, 2019: 52). 
que sin duda conoce mejor ${ }^{14}$, al medio cinematográfico, y no un traductor de Heidegger al mismo medio.

Ciertamente, en el cine de Malick "abundan las referencias bíblicas" (Michaels, 2009: 46), incluso en un nivel superficial. Por ejemplo: el título de su segundo largometraje, Días del cielo, proviene de un versículo del Libro del Deuteronomio (11,21); El árbol de la vida comienza con una cita del Libro de Job $(38,4.7)$; uno de los protagonistas de To the Wonder es un sacerdote católico, cuyos sermones aluden constantemente a la Biblia; al inicio de Knight of Cups escuchamos una narración en off de El progreso del peregrino de John Bunyan, un libro que bebe de la Carta a los Hebreos 11,13; Song to Song concluye con el poema La imagen divina de William Blake, basado en Génesis 1,26; Vida oculta cuenta la historia del católico Franz Jägerstätter, cuyo encarcelamiento y ejecución a manos de los nazis reflejan los padecimientos de Cristo; y, por último, el siguiente largometraje del cineasta — cuyo título provisional es The Last Planet- está aparentemente inspirado en los evangelios.

Sin embargo, el intento de sustentar la influencia de la Biblia en la obra de Malick sobre un puñado de referencias a la Escritura no haría más que repetir lo que los autores antes citados han hecho con Heidegger. De nuevo, existiría un subtexto oculto - bíblico, en este caso- que solo un espectador privilegiado - conocedor de la Biblia - podría desenterrar. Pero tampoco en este caso resultaría legítimo hacer una interpretación así. "En situaciones como esta, donde las imágenes del filme parecen sugerir un significado oculto, necesitamos ser especialmente cautelosos, teniendo cuidado de no caer en la trampa [...] de extraer un significado del filme, de decodificar el mensaje subyacente al filme" (2019: 79), advierte Heber-Percy en un libro sobre cine y fe cristiana. Por el contrario, este autor propone un modo distinto de dar con el significado de películas tan abiertas como las de Malick: la solución no es "desvelar un concepto [...], sino discernir qué efecto tiene este [filme] en nosotros" (Heber-Percy, 2019: 11), pues es ahí donde se encuentra su significado. En última instancia, Heber-Percy reivindica la capacidad que tiene el cine para provocar un hondo cambio interior en el espectador, equiparable a lo que se conoce como "conversión" religiosa. "Asumiré a modo de argumento - pero también desde la convicción personal - que la experiencia de ver una película puede ser una conversión, una metanoia" (2019: 8), sostiene Heber-Percy.

Esta noción de conversión (metanoia, en griego) —específicamente cristiana, y distinta de la catarsis aristotélica, dado que la conversión privilegia un efecto positivo y la catarsis uno negativo ${ }^{15}$ - es explicada por este autor con unas palabras del teólogo Stephen B. Bevans: "Algunas cosas requieren un cambio radical de perspectiva, un cambio de horizonte - una conversión - antes de que empiecen a cobrar sentido" (La cursiva es del original. 2002: 103). En su Introducción al cristianismo, Joseph Ratzinger añade algo a esta noción: dice que la conversión supone dejar de confiar solamente en lo que los ojos pueden ver y que, por ese motivo, "siempre tiene algo de ruptura arriesgada y de salto, porque en todo tiempo implica la osadía

\footnotetext{
Véase la tesis doctoral de Pierre de Cabissole, La Bible dans l'oeuvre de Terrence Malick (2003).

15 Para Aristóteles (Poética 1449b27) la catarsis (kátharsis) consiste en la purificación de las emociones trágicas: la compasión (éleos) y el temor (phóbos). El efecto catártico de la tragedia es, por tanto, eminentemente negativo (véase Labrada, 2017: 44-49). En la conversión cristiana, en cambio, predomina un efecto positivo: una renovación de la vida, caracterizada por actitudes como el amor, el fervor, el servicio, la alegría o la paciencia (véase Romanos 12,1-13). El cine de Malick parece estar más orientado hacia este segundo efecto.
} 
de ver en lo que no se ve lo auténticamente real"' (2001 [1968]: 49). En algunos personajes de Malick se aprecia un cambio de este tipo: la mirada asombrada de Witt instantes antes de morir abatido a tiros en La delgada línea roja; el hallazgo final de Pocahontas, junto a su hijo, en los jardines de Hampton Court en El nuevo mundo; la decisión de Jack de cruzar la puerta estrecha en mitad del desierto en El árbol de la vida o el descubrimiento de Cristo por parte del Padre Quintana en To the Wonder son ejemplos concretos de conversión, en el sentido aquí señalado ${ }^{16}$. En todos estos casos se produce esa vuelta de un personaje hacia un ámbito invisible. Retomando las reflexiones de Heber-Percy sobre la capacidad transformadora del séptimo arte, cabe preguntar si el cine de Malick está invitando al espectador a adoptar la conversión vivida por sus personajes.

\section{La transformación de la mirada}

En un estudio sobre la dimensión teológica del cineasta texano, Calhoun afirma que sus películas "subrayan la posibilidad de la conversión, tanto para los personajes dentro de la narrativa como para los espectadores que son introducidos en el relato" (2016: 78). Este autor señala cómo los filmes de Malick crean en el nivel narrativo un conflicto trasladable a la experiencia del espectador. Dicho de otra forma, estas películas buscan cuestionar la visión del mundo que tiene el espectador — su "marco interpretativo" o interpretive framework, en palabras de Calhoun- mediante una estrategia que se apoya tanto en el nivel narrativo como en el nivel estético - referido al uso del lenguaje cinematográfico-. En el primer nivel se da un choque entre visiones opuestas del mundo, encarnadas por los protagonistas, y el posterior cambio o conversión de algunos; en el segundo nivel se observan una serie de decisiones estéticas que parecen traducir esa conversión al lenguaje visual y sonoro. En muchas ocasiones, la conversión de los protagonistas es expresada por medio de voces off que aluden a un modo particular de mirar las cosas que se refleja — a su vez- en la mirada de la cámara. Podría decirse que, mediante esta estrategia, el espectador es invitado a mirar las cosas de un modo nuevo ${ }^{17}$; a este respecto, Caruana escribe, en su estudio sobre El árbol de la vida, que este cambio "implica renovación, una transformación en cómo uno percibe el mundo" (2018: 78).

Esta alusión de las voces en off a la mirada se encuentra, de forma clara, en dos escenas de La delgada línea roja. Después de la última conversación entre Witt y Welsh, mientras el segundo camina entre otros soldados al atardecer, se escuchan estas palabras: "Un hombre mira a un pájaro muriéndose y piensa que no hay sino dolor sin respuesta. Que la muerte tiene la última palabra; se está riendo de él. Otro hombre mira a ese mismo pájaro, siente la gloria; siente algo que sonríe a través de este" [One man looks at a dying bird and thinks there's nothing but unanswered pain. That death's got the final word; it's laughing at him. Another man sees that same bird, feels the glory; feels something smiling through it]. Por otra parte, al final de

16 Se profundiza en este rasgo de los personajes de Malick en El cine de Terrence Malick. La esperanza de llegar a casa; véase el capítulo "Personajes en busca de Dios" (Alzola, 2020: 117-130).

17 Resulta muy elocuente el prefacio del primer borrador del guion de El árbol de la vida, fechado en 2007: "El ‘yo’ que habla en esta historia no es el autor. Más bien, él espera que tú puedas verte en este ‘yo' y entiendas esta historia como la tuya". 
la película — cuando las tropas de la Compañía Charlie se retiran de Guadalcanalresuena esta última voz en off: "Oh, alma mía, déjame ahora estar en ti. Mira a través de mis ojos. Mira hacia las cosas que has hecho. Todas las cosas resplandecen" [Oh, my soul, let me be in you now. Look out through my eyes. Look out at the things you made. All things shining]. También en El árbol de la vida hay dos voces en off similares: al comienzo, la voz en off de Mrs. O'Brien habla de los dos caminos en la vida, el "camino de la naturaleza" [the way of nature] y el "camino de la gracia" [the way of grace], y dice que el primero "encuentra razones para ser infeliz cuando todo el mundo resplandece a su alrededor, y el amor sonríe a través de todas las cosas" 18 [finds reasons to be unhappy when all the world is shining around it, and love is smiling through all things]. Mr. O'Brien, quien encarna este camino, experimenta un cambio interior al final del filme - cuando pierde su empleo, su mundo se derrumba - y lo expresa con las siguientes palabras: "No soy nada. Mirad la gloria a nuestro alrededor; árboles y pájaros. Vivía en la vergüenza. Todo lo deshonraba y no percibía la gloria"19 [I'm nothing. Look at the glory around us; trees, birds. I lived in shame. I dishonored it all, and didn't notice the glory]. Son semejantes las voces en off del Padre Quintana en To the Wonder, "Brilla a través de nosotros. Enséñanos cómo buscarte. Estamos hechos para verte"20; del padre de Rick en Knight of Cups, "Encuentra la luz que conocías en el Este cuando eras un niño"21 [Find the light you knew in the East as a child]; o de Franz en Vida oculta, "Tú, nuestra luz. La oscuridad no es oscura para ti. Llévanos a tu luz eterna. A ti, la verdadera, la luz que nunca se apaga"22 [You our light. Darkness is not dark to you. Bring us to your eternal light. To you, the true, the never-failing light]. En todas estas voces sobresale la importancia de la mirada - como vehículo para una comprensión del mundo-y su cambio hacia una forma nueva de ver.

Se plantea ahora la pregunta sobre qué es lo que descubren estas miradas. La respuesta es la misma en todos los filmes mencionados: ese descubrimiento consiste en una luz que antes pasaba desapercibida, y que algunos personajes llaman "gloria". En realidad, se trata de una luz que la cámara ya había mostrado al espectador antes de que los personajes la encontraran; "la cámara permanece como un testigo silencioso de la gloria que de hecho es evidente en la naturaleza, y espera ser percibida y reconocida" (Calhoun, 2016: 80). Ciertamente, en muchas escenas de las películas de Malick destaca la atención de la cámara hacia la luz que resplandece en todas las cosas, algo que había sido advertido por Cavell en su análisis de Días del cielo (2017: 18). Esta luz aparece en el último plano de Malas tierras, donde un sol

18 La traducción de las voces en off y diálogos de la versión original en inglés sigue casi siempre la de los subtítulos en castellano disponibles en la edición española en DVD, aunque hay pequeñas modificaciones cuando la traducción no se ha considerado ajustada. Cfr. El árbol de la vida [DVD distribuido en España por Tripictures, Dep. Legal M-39010-2011].

19 Esta voz en off está inspirada en la novela de Dostoievski Los hermanos Karamázov, donde el hermano del stáret Zósima dice unas palabras similares al recuperar su fe perdida: "Sí, toda esta gloria divina estaba a mi alrededor: pájaros, árboles, prados, cielos; solo yo vivía en la vergüenza, y solo lo deshonraba todo, y no veía la hermosura y la gloria" (Dostoievski, 1997: 458).

20 En español en la versión original.

21 La traducción de las voces en off y diálogos de la versión original en inglés es del autor, a partir de la edición inglesa en DVD. Cfr. Knight of Cups [DVD distribuido en el Reino Unido por Studiocanal Limited, 2015].

22 La traducción de las voces en off y diálogos de la versión original en inglés es del autor. Cfr. Vida oculta [Distribuida en cines por Fox Searchlight Pictures, y en España por The Walt Disney Company]. 
crepuscular brilla a través de las nubes; en La delgada línea roja, cuando los rayos del sol atraviesan la vegetación, bañando el futuro campo de batalla de una misteriosa luminosidad; en El árbol de la vida, donde el destello del sol entre los árboles parece responder a las plegarias del pequeño Jack; o en el recuerdo final de Franz en Vida oculta - él conduciendo una motocicleta, bajo un sol radiante - antes de ser ejecutado por los nazis. En el fondo, esta luminosidad capturada por la cámara actúa como signo de la presencia de un Dios que se manifiesta a sí mismo como luz. A propósito de El árbol de la vida, Rothman apunta cómo "el filme de Malick justifica sus imágenes no reconociéndolas como la obra de un mero autor humano, sino presentándolas como emanaciones, o manifestaciones, de Dios. En el filme, Dios es luz. Las imágenes cinematográficas están escritas en luz" (2016: 49). Esta caracterización de la luz como manifestación de la divinidad hunde sus raíces en la tradición cristiana, y encuentra su expresión justa en el término "gloria"23.

De acuerdo con lo aquí expuesto, podría decirse que esta estrategia - que empareja la conversión de algunos personajes con la mirada de una cámara abierta a la luminosidad de las cosas - invita al espectador a ver de un modo nuevo el mundo que le rodea. Esta invitación cobra especial fuerza en el momento en que el mundo de los personajes se derrumba: cuando el mundo idílico de Witt — su vida en comunión con los nativos melanesios - se desvanece, cuando Mr. O'Brien entra en crisis tras perder su empleo o cuando el Padre Quintana, Rick y Franz se hallan en la más completa oscuridad interior. En resumen, cuando el mundo humano en el que viven estos personajes - el mundo de Heidegger, aquel que da "medida y finalidad y validez" a sus acciones, en palabras de Malick (2016: 252)— se quiebra, se abre también un resquicio a la conversión. En la misma medida, este cine "es una invitación para el espectador a cambiar, a adoptar una actitud diferente hacia la vida [...] Nos enfrenta con lo que significa para el individuo experimentar la ruina de su mundo, su pérdida radical" (2018: 70-71), sostiene Caruana. Se revela, de esta forma, la persistencia de un sentido más allá de los esfuerzos humanos; "algo que uno recibe inmerecidamente sin la seguridad de un resultado previsto" (Caruana, 2018: 74). Esta convicción de que el sentido más fundamental no puede ser construido, sino que ha de ser acogido, permanece en el centro de la fe cristiana ${ }^{24}$. En definitiva, el cine de Malick plantea al espectador algo que no está presente en Heidegger ${ }^{25}$ : la presencia de lo invisible - de Dios - en la vida ordinaria del ser humano.

23. En un estudio sobre El árbol de la vida y Song to Song, Zocchi explica — apoyada en la estética teológica de Hans Urs von Balthasar - el significado del término gloria dentro de la tradición cristiana. Dice que la gloria resulta de la trasfiguración —o transformación — de la realidad natural por la gracia, es decir, por la acción misteriosa de Dios: "En este sentido, digo que gloria no es sinónimo de gracia, sino el resplandor de una gracia que ya siempre estaba presente en la naturaleza, una que requiere la libertad humana para ser reconocida y, por tanto, resplandecer frente a nuestros ojos" (Zocchi, 2018: 7).

24 Así lo explica Ratzinger en su Introducción al cristianismo: “Creer cristianamente significa [...] afirmar que el sentido que nosotros no podemos construir, que solo nos es dado recibir, se nos ha regalado, de manera que lo único que tenemos que hacer es aceptarlo y fiarnos de él. Según eso, la fe cristiana es optar a favor de que lo recibido precede al hacer. [...] La fe cristiana significa también, como hemos dicho, considerar lo invisible como más real que lo visible" (2001: 67).

25 En De la esencia del fundamento, Heidegger se sitúa claramente al margen de la cuestión de Dios: "Mediante la interpretación ontológica del Dasein en cuanto ser-en-el-mundo, no se toma ninguna decisión, ni positiva ni negativa, sobre un posible ser en relación con Dios [sic]" (2001: 159, nota 88). Colomer aclara que "el análisis existencial heideggeriano ni incluye ni excluye la cuestión de Dios. Esta cuestión se sitúa fuera de su ámbito metódico" (2002: 620). 


\section{Conclusiones}

Este estudio ha partido de la caracterización de Terrence Malick como traductor. Según se ha apuntado, el hecho de que el cineasta se dedicara durante unos años a la filosofía académica y tradujera al inglés el opúsculo De la esencia del fundamento (2001 [Vom Wesen des Grundes, 1929]) de Martin Heidegger ha sido tomado por algunos autores como clave interpretativa de su cine. En última instancia, este artículo ha buscado poner en duda esta afinidad entre Heidegger y Malick, proponiendo la hipótesis de que la obra del cineasta texano está alentada por una visión del mundo de raíces cristianas. El epígrafe segundo de este artículo ha presentado una panorámica de las aportaciones más relevantes en lo que respecta a la posible afinidad entre el pensamiento de Heidegger y el cine de Malick, recurriendo al concepto de mundo del filósofo alemán como hilo conductor de todas ellas; se han destacado los estudios de Cavell (2017 [1979]), Furstenau y MacAvoy (2007 [2003]), Clewis (2003), Sinnerbrink (2006), Silverman (2009), Dreyfus y Prince (2009), Woessner (2011), Rybin (2011) y Tucker (2011). En síntesis, este concepto de mundo se refiere a un entramado de relaciones que constituyen el horizonte de sentido en el que se inserta la vida del ser humano (Rodríguez, 2006: 89). Es el mundo, y no Dios, el horizonte hacia el que trasciende el ser humano en su existencia cotidiana; por tanto, el análisis existencial llevado a cabo por Heidegger se sitúa al margen de la cuestión de Dios (Colomer, 2002: 619-634). Podría añadirse, a este respecto, que una interpretación heideggeriana del cine de Malick no negaría una interpretación cristiana; las dos serían complementarias. En cualquier caso, la segunda parece prevalecer sobre la primera, como se ha mostrado en la segunda parte del artículo.

Además, una interpretación de la obra de Malick que se ciñese únicamente al concepto heideggeriano de mundo no haría justicia a la naturaleza propia del medio cinematográfico; tampoco a los verdaderos intereses que animan este cine. Así lo sostienen estudios como los de Harrison (2020), Fijo (2019) o Heber-Percy (2019), los cuales advierten - según ha quedado expuesto en los epígrafes tercero y cuarto- contra el error de entender el significado del cine a partir de un presunto subtexto filosófico oculto. Más bien, el significado de las películas de Terrence Malick ha de ser dilucidado a partir del efecto que estas tienen en los espectadores, es decir, de la experiencia que tratan de suscitar en ellos. Se ha visto en el epígrafe quinto cómo estas películas, sobre todo desde La delgada línea roja, invitan a sus espectadores a adoptar "un cambio radical de perspectiva" (Bevans, 2002: 103) frente al mundo - una "conversión", en el sentido religioso del término- análogo al que viven sus protagonistas. Este cambio, mostrado por las películas en el nivel narrativo mediante la voz en off de algunos personajes, tiene su eco en el nivel estético - el lenguaje cinematográfico-, y especialmente en la mirada de una cámara abierta a la luminosidad de las cosas. Esta correspondencia entre el nivel narrativo y el estético - entre la voz en off y la mirada de la cámara- identifica la luz que proyecta el cine de Malick como signo de la "gloria"; en el fondo, como signo de la transformación de todas las cosas por medio de la presencia misteriosa de Dios (Rothman, 2016: 49; Zocchi, 2018: 7).

Al final, sin embargo, permanecen dos cuestiones que no han sido abordadas en las páginas precedentes: por una parte, no queda del todo claro por qué las revelaciones de la obra de Malick - la gloria - han de tener un significado específicamente cristiano; por otra, cabe preguntar si acaso dicho significado es un punto de llegada 
ineludible para todo espectador de estas películas. En relación a la primera pregunta, es preciso hacer notar cómo la citada confluencia de la voz en off de los personajes - expresión de su cambio interior - con la luminosidad captada por la cámara es a su vez respaldada por las referencias directas de este cine a la Biblia cristiana -Antiguo y Nuevo Testamento-, algunas de ellas citadas al comienzo del cuarto epígrafe. En el fondo, estas citas no contribuyen a la unidad narrativa o estética del filme, pero sí aclaran qué clase de cambio interior atraviesan sus protagonistas, y de qué naturaleza es el descubrimiento que realizan. Finalmente, en respuesta a la segunda pregunta se podría argumentar lo mismo que dice Calhoun en su estudio sobre el cineasta texano: "Cualquier fuerza que Malick ejerce en sus filmes es persuasiva más que agresiva o coercitiva. Es decir, es una invitación" (2016: 87). El cambio de perspectiva frente al mundo, la conversión, no puede darse sin la participación de la libertad del sujeto ni, en último término, sin la acción misteriosa de Dios en él. Esta es una cuestión que escapa al alcance de este artículo - y que concierne a todo ese modo en que Dios se revela al mundo-, cuyo fin ha sido solamente plantearla en los términos propios del cine de Terrence Malick.

\section{Financiación}

Este trabajo se enmarca en el proyecto de investigación "La crisis del European Dream: hogar, identidad y éxodo en las artes audiovisuales", financiado por el Ministerio de Ciencia, Innovación y Universidades, referencia HAR2017-85846-R.

\section{Bibliografía}

Alzola, P. (2020). El cine de Terrence Malick. La esperanza de llegar a casa. Pamplona: EUNSA.

Alzola, P. (2016). "Al encuentro de la muerte: una lectura del primer cine de Terrence Malick desde la filosofía de Martin Heidegger". La Torre del Virrey. Revista de Estudios Culturales, vol. 20, núm. 2, 19-88.

Aristóteles. (2010). Poética. Trad. Alicia Villar Lecumberri. Madrid: Alianza Editorial.

Barnett, C. B. (2013). "Spirit(uality) in the Films of Terrence Malick". Journal of Religion \& Film, vol. 17, núm. 1, 1-29.

https://digitalcommons.unomaha.edu/jrf/vol17/iss1/33/

Bevans, S. B. (2002). Models of Contextual Theology. Nueva York (NY): Orbis.

Cabissole, P. de (2003). La Bible dans l'oeuvre de Terrence Malick. París: Sorbonne Nouvelle.

Cabrera, J. (2015 [1999]). Cine, 100 años de filosofia. Una introducción a la filosofia a través del análisis de películas. Segunda edición. Barcelona: Gedisa.

Calhoun, D. H. (2016). "Who Has Eyes to See, Let Him See. Terrence Malick as Natural Theologian”. En Christopher B. Barnett \& Clark J. Elliston (eds.), Theology and the Films of Terrence Malick. Londres/Nueva York (NY): Routledge, 66-98. https://doi. org/10.4324/9781315743158

Caruana, J. (2018). "Repetition and Belief. A Kierkegaardian Reading of Malick's The Tree of Life". En John Caruana \& Mark Cauchi (eds.), Immanent Frames. Postsecular Cinema between Malick and von Trier. Nueva York (NY): SUNY Press. 
Cavell, S. (2017 [1979]). El mundo visto. Reflexiones sobre la ontología del cine. Trad. Antonio Fernández Díez. Córdoba: UCOPress.

Cavell, S. (2007 [2004]). Ciudades de palabras. Cartas pedagógicas sobre un registro de la vida moral. Trad. Javier Alcoriza \& Antonio Lastra. Valencia: Pre-Textos.

Casciaro, J.M. (coord.). Sagrada Biblia. (2001). Pamplona: EUNSA.

Chion, M. (2004). The Thin Red Line. Trad. Trista Selous. Londres: British Film Institute.

Clewis, R. (2003). "Heideggerean Wonder in Terence Malick's The Thin Red Line". Film and Philosophy, vol. 7, núm. 1, 22-36. https://doi.org/10.5840/filmphil200373

Colomer, E. (2002). El pensamiento alemán de Kant a Heidegger. Tomo tercero: El postidealismo. Barcelona: Herder.

Critchley, S. (2002). “Calm. On Terrence Malick's The Thin Red Line”. Film-Philosophy, vol. 6, núm. 1. https://doi.org/10.3366/film.2002.0023

Dostoievski, F. M. (1997). Los hermanos Karamázov. Trad. Natalia Ujanova. Madrid: Cátedra.

Dreyfus, H. \& Prince, C. S. (2009). "The Thin Red Line: Dying without Demise, Demise without Dying". En David Davies (ed.), The Thin Red Line. Londres/Nueva York (NY): Routledge, 29-44.

Fijo, A. (2019). Terrence Malick. Una aproximación. Sevilla: FilaSiete Libros de Cine.

Fijo, A. (2017). "El árbol de la vida (Terrence Malick, 2011) como reivindicación del gran relato ontoteológico en el cine". En Enrique Fuster (ed.), Identidad y reconocimiento en cine y televisión. Roma: EDUSC, 159-179.

Furstenau, M. \& MacAvoy, L. (2007 [2003]). “Terrence Malick’s Heideggerian Cinema: War and the Question of Being in The Thin Red Line". En Hannah Patterson (ed.), The Cinema of Terrence Malick. Poetic Visions of America. Second Edition. Londres/Nueva York (NY): Columbia University Press, 179-191.

Harrison, B. (2020). “The New World: Heideggerian or Humanist Cinema?”. Aesthetic Investigations, vol. 3, núm. 2, 200-227. Recuperado de https://www.aestheticinvestigations.eu/ index.php/journal/article/view/223

Heber-Percy, C. (2019). Perfect in Weakness. Faith in Tarkovsky's Stalker. Eugene (OR): Wipf and Stock Publishers.

Heidegger, M. (2012 [1927]). Ser y tiempo. Trad. Jorge Eduardo Rivera. Madrid: Trotta. [Sein und Zeit. (1927). Tübingen: Niemeyer]

Heidegger, M. (2010 [1935/36]). "El origen de la obra de arte". En Caminos de bosque. Trad. Helena Cortés y Arturo Leyte. Madrid: Alianza Editorial, 7-68. ["Der Ursprung des Kunstwerkes”. (1935/36). En Gesamtausgabe. Band 5: Holzwege. (1950). Frankfurt: Vittorio Klostermann, 7-68]

Heidegger, M. (2001 [1929]). “De la esencia del fundamento". En Hitos. Trad. Helena Cortés y Arturo Leyte. Madrid: Alianza Editorial, 123-175. ["Vom Wesen des Grundes". (1929). En Gesamtausgabe. Band 9: Wegmarken. (1976). Frankfurt: Vittorio Klostermann, 123175]

Labrada, M. A. (2017). Consideraciones filosóficas sobre la belleza y el arte. Pamplona: EUNSA.

Leyte, A. (2016). Post sciptum a El origen de la obra de arte de Martin Heidegger. Madrid: La Oficina.

Livingston, P. \& Plantinga, C. (eds.). (2009). The Routledge Companion to Philosophy and Film. Londres/Nueva York (NY): Routledge. https://doi.org/10.4324/9780203879320

Malick, T. (2016 [1969]). "Translator's Introduction to Martin Heidegger The Essence of Reasons (Vom Wesen des Grundes)". En Jonathan Beever \& Vernon W. Cisney (eds.), The 
Way of Nature and the Way of Grace. Philosophical Footholds on Terrence Malick's The Tree of Life. Evanston (IL): Northwestern University Press, 251-255.

Malick, T. (2007). "First Draft of The Tree of Life. A Screenplay by Terrence Malick". Writers Guild of America (registrado el 25 de junio de 2007). Recuperado de https://indiegroundfilms.files.wordpress.com/2014/01/tree-of-life-the-jun-25-07-1st.pdf (Fecha de acceso: 28/04/2020).

Michaels, L. (2009). Terrence Malick. Champaign, IL: University of Illinois Press.

Mulhall, S. (2016 [2001]). On Film. 3rd Edition. Londres/Nueva York (NY): Routledge. https://doi.org/10.4324/9781315757599

Muñoz Fernández, H. (coord.). (2020). Filosofía y cine. Filosofía sobre cine y cine como filosofía. Zaragoza: Prensas de la Universidad de Zaragoza.

Patterson, H. (2007 [2003]). "Introduction: Poetic Visions of America”. En Hannah Patterson (ed.), The Cinema of Terrence Malick. Poetic Visions of America. Second Edition. Londres/Nueva York (NY): Columbia University Press, 1-13.

Pippin, R. B. (2017). Hitchcock filósofo. Vértigo y las ansiedades del desconocimiento. Trad. Tania Martínez. Córdoba: UCOPress.

Ratzinger, J. (2001 [1968]). Introducción al cristianismo. Trad. José L. Domínguez Villar \& José María Hernández Blanco. Salamanca: Sígueme.

Read, R. \& Goodenough, J. (eds.) (2005). Film as Philosophy. Essays in Cinema after Wittgenstein and Cavell. Basingstoke: Palgrave Macmillan. https://doi. org/10.1057/9780230524262

Rodríguez, R. (2006). Heidegger y la crisis de la época moderna. Madrid: Síntesis.

Rybin, S. (2011). "Voicing Meaning: On Terrence Malick's Characters". En Thomas Deane Tucker \& Stuart Kendall (Eds.), Terrence Malick. Film and Philosophy. Londres/Nueva York (NY): Continuum, 13-39. https://doi.org/10.5040/9781628928990.ch-002

Rothman, W. (2016). "Seeing the Light in The Tree of Life". En Jonathan Beever \& Vernon W. Cisney (eds.), The Way of Nature and the Way of Grace. Philosophical Footholds on Terrence Malick's The Tree of Life. Evanston (IL): Northwestern University Press, 35-58.

Silverman, K. (2009). All Things Shining. En Flesh of My Flesh. Stanford (CA): Stanford University Press, 107-132.

Sinnerbrink, R. (2019). Terrence Malick. Filmmaker and Philosopher. Londres/Nueva York (NY): Bloomsbury.

Sinnerbrink, R. (2006). "A Heideggerian Cinema? On Terrence Malick's The Thin Red Line”. Film-Philosophy, vol. 10, núm. 3. https://doi.org/10.3366/film.2006.0027

Tucker, T. D. (2011). "Worlding the West: An Ontopology of Badlands". En Thomas Deane Tucker \& Stuart Kendall (Eds.), Terrence Malick. Film and Philosophy. Londres/Nueva York (NY): Continuum, 80-100. https://doi.org/10.5040/9781628928990.ch-005

Wartenberg, T. E. (2007). Thinking on Screen: Film as Philosophy. Londres/Nueva York (NY): Routledge. https://doi.org/10.4324/9780203030622

Woessner, M. (2011). "What Is Heideggerian Cinema? Film, Philosophy, and Cultural Mobility". New German Critique, vol. 38, núm. 2 (113), 129-157. https://doi.or$\mathrm{g} / 10.1215 / 0094033 \mathrm{X}-1221803$

Zocchi, E. (2018). "Terrence Malick Beyond Nature and Grace: Song to Song and the Experience of Forgiveness". Journal of Religion \& Film, vol. 22, núm. 2, 1-34. https://digitalcommons.unomaha.edu/jrf/vol22/iss2/3/ 